\title{
LA CUMBRE IBEROAMERICANA: OPORTUNIDAD PARA QUE Y PARA QUIEN
}

\author{
Ernesto Samper Pizarro (*)
}

\section{EL CONTEXTO DE LA REGIONALIZACION}

La próxima celebración de la Cumbre Iberoamericana constituye una excelente oportunidad para intentar una nueva lectura de las relaciones entre España y Latinoamérica y plantear, a partir de allí, espacios e instrumentos a través de los cuales se cristalice una nueva relación, acorde con la vecina europeización de España y la inevitable conformación de un bloque hemisférico entre las Américas. Este ensayo se separa de quienes piensan, con cierto pesimismo, que el precio del ingreso de España a la Comunidad será su alejamiento e inclusive su ruptura con América Latina. Al contrario, plantea la tesis de que el peso político especifico de España dentro de la Comunidad estará directamente relacionado con su capacidad para mantener una relación profunda con Latinoamérica. Y agrega que para que dicha relación sea productiva de manera permanente, debe buscar la consolidación de los procesos regionales de integración y la defensa de su democracia a través de la superación de la crisis social que desde hace varios años aqueja al continente. No es de extrañar por ello que nuestra inmediata aspiración sea la de que silmultáneamente con el Plan de Convergencia a través del cual se profundizará la integración comunitaria, se avance en el diseño de un PLAN IBEROAMERICA que debe reformular nuestras relaciones hacia otro largo camino de vecindad por quinientos años más.

\section{LA REGIONALIZACION COMO REALIDAD GEOPOLITICA}

El anterior planteamiento supone la aceptación de una nueva realidad geopolítica: la regionalización. La desaparición de la amenaza de la guerra fría que polarizaba ideológicamente al mundo hasta hace unos meses; el virtual fracaso del GATT por presiones motivadas por intereses regionales como el agrícola de Europa o la insistencia de todos los países industralizados por relegar a segundo plano las expectativas de los países en desarollo colocando en primer orden sus aspiraciones como la protección de la propiedad intelectual o el asegurar la libre movilidad de capitales; la agresiva postura japonesa frente a la consolidación de un frente asiático de comercio; la evidente etapa de introspección que inició Europa con la firma del Tratado de Maastricht, entre otros factores, comprueban claramente que los intentos por una relación global entre países están fracasando y que la regionalización y la integración de bloques están en el orden actual de prioridades. Esto, para el caso que nos ocupa en este ensayo, significa aceptar, como marco de la nueva integración iberoamericana, que España estará jugando desde Europa y América Latina desde el bloque americano.

\section{LA INICIATIVA PARA LAS AMERICAS}

Está claro que uno de los primeros escollos en este planteamiento se encuentra en que España va más rápido que Latinoamérica en la conformación de su bloque de referencia. La Iniciativa Bush para las Américas que pretende, al terminar este siglo, dejar sentadas las bases para una integración hemisférica ha corrido más rápidamente en su formulación que en sus realizaciones. Contiene, en efecto, elementos importantes para la redifinición de un nuevo marco de entendimiento entre Estados Unidos y América Latina en la medida en que está formulada desde la óptica de la Secretaría del Tesoro como una verdadera propuesta de integración económica que contrasta con antiguas aproximaciones políticas que tenían más el sabor de la congratulación efímera que de la solidaridad a largo plazo. La Iniciativa parte además de una nueva realidad, diferente a las anteriores: Estados Unidos necesita hoy mucho más que ayer a América Latina. Necesita sus mercados, sus posibilidades de inversión, su capacidad de trabajo. Como lo ha señalado el periodista ANDREU CLARET en La Vanguardia de Barcelona : "En 1991 América Latina fue por primera vez en su historia el segundo socio comercial de Estados Unidos después de la C.E.: es una buena señal". Lo importante para América Latina es que, en ausencia del GATT, la nueva integración continental no se haga a destajo, separadamente a través de acuerdos bilaterales. La reactivación de viejos escenarios e instrumentos de integración cuyo agotamiento fue consecuencia de la asfixia de los viejos moldes proteccionistas, como la ALADI, parece necesaria esta vez para consolidar las aspiraciones de los cuatrocientos millones de latinoamericanos que desean obtener de la integración esta vez sí, beneficios concretos. De lo que ahora se trata no es de integrarnos hacia adentro, creando una muralla china de protecciones arancelararios, como de integrarnos hacia afuera para buscar, a través de la internacionalización, la modernización de los procesos económicos y sociales. A esa realidad integrada deberemos llegar por distintos caminos, el de los acuerdos subregionales, como el del NAFTA, el G-3, el Grupo Andino o el Mercosur, también por el de las negociaciones multilaterales. En la búsqueda de la integración para el progreso y la democracia, la nueva relación iberoamericana tendrá mucho que ver en la medida en que España tenga la capacidad de 
colocar a Europa de contrapeso de las aspiraciones latinoamericanas en el contexto de la integración de las Américas.

\section{LA NUEVA IDEA LATINOAMERICANA}

Asi entendida, la Cumbre de Iberoamérica, más allá de la declaración de principios de Guadalajara, encomiable como toda declaración de principios, deberá tener presente en sus deliberaciones, la existencia de una NUEVA IDEA LATINOAMERICANA. América Latina no ha estado, ciertamente, en el cátalogo reciente de las preocupaciones mundiales. Su participación en el comercio mundial cayó de manera dramática en los últimos diez años. Con la reducción del producto bruto por habitante como consecuencia del pago de la deuda externa, se redujeron también las posibilidades de progreso y bienestar conseguidas, con mucho esfuerzo, en las décadas anteriores. Como ejemplo dramático estamos recuperando hoy el nivel de ingreso de 1977. El terrorismo, la corrupción y los efectos sociales de un ajuste impuesto, con la complicidad de tecnócratas criollos, por las agencias internacionales de crédito, están dando al traste con los esfuerzos democratizadores conseguidos a lo largo de los últimos diez años. Los casos recientes de desestabilización democrática prueban, claramente que estamos lejos de poder celebrar el desmoronamiento del mito comunista como el triunfo definitivo de la ideología capitalista contra el socialismo centralizado. Al contrario, todo apunta a indicar que la desaparición del "enemigo externo" ha potencializado los virus internos del sistema revelando la presencia de una fuerte patología antidemocrática. La enfermedad sólo podrá conjugarse con una receta de crecimiento con equidad, el viejo sueño del desarrollo latinoamericano. En la tarea del fortalecimiento de la democracia regional está aún por definirse el papel que deben cumplir algunos países industralizados, más interesados hoy en la protección coactiva de sus intereses que en el respeto de principios como el de la no intervención en los asuntos internos de los Estados; interesados más en la profundización de los procesos de ajuste económico en su capacidad de liberación inmediata de poder de compra para sus exportaciones que en los efectos estabilizadores en el corto plazo de las formulaciones neoliberales, como el aumento coyuntural del desempleo, el desabastecimiento alimentario o el derrumbe de la pequeña empresa, los países industrializados están subestimando el impacto que sobre la democracia latinoamericana está produciendo la aceleración del ajuste macroeconómico. La solidaridad democrática debe por ello convertirse en razón de ser y de actuar del nuevo compromiso iberoamericano. Ahora nos corresponde a los latinoamericanos recordar el vehemente anhelo de Tocqueville cuando maravillado de la democracia indígena americana manifestaba que "tarde o temprano los franceses alcanzaremos, como los americanos, la igualdad de oportunidades".

\section{EL PLAN IBEROAMERICA}

El Plan Iberoamérica deberá contener ingredientes parecidos a aquellos del V Centenario que hoy resultan celebrables. La nueva relación no podrá ser en ningún caso una relación convencional. Tendrá que ser tanto o más profunda como la revolución de esa peculiar simbiosis del mestizaje que sintetiza el resultado de quinientos años de empresas militares, evangelizaciones, expediciones científicas y operaciones comerciales. Y así como América le devolvió al viejo Mundo la capacidad de sorpresa que es, según Einstein, la materia prima del progreso científico, así también, ahora el nuevo estadio iberoamericano deberá marcar un nuevo hito en las relaciones constructivas que van desde la responsabilidad compartida de consolidar los avances democráticos hasta la definición de nuevos instrumentos de interacción que nos permitan pasar de la búsqueda romántica de la hispanidad a la realidad práctica de la nueva Iberoamérica.

\section{EL FORO POLITICO}

De la cumbre debería resultar, en primer lugar, un FORO POLITICO, un escenario permanente, al más alto nivel, a través del cual se protocolizará el seguimiento periódico de una agenda iberoamericana. Un encuentro periódico de Presidentes, por ejemplo, con una reunión preparatoria de cancilleres atendida por una Secretaría permanente. Las experiencias recientes de procesos de integración subregional en Latinoamérica, como el Grupo Andino, han probado la bondad de un esquema de este tipo. Los mayores enemigos de los esfuerzos de integración son los burócratas cuya supervivencia está en proporción directa a su capacidad para demorar procesos e imaginar dificultades. EL FORO garantizaría el desarrollo de un itinerario de acciones, actualizándolo con la periodicidad necesaria para introducir revisiones y modificaciones que mantengan la credibilidad en el proceso.

\section{LA AGENDA DE LA CUMBRE}

Son muchos los temas que podrían incluirse en la agenda de la Cumbre. Existe, sin embargo, un horizonte mínimo de aspiraciones que debería ser tenido en cuenta. Está, en primer lugar, la necesidad de buscar formas efectivas de integración económica. La experiencia reciente en materia de procesos de integración demuestra que la idea tradicional de la integración como intercambio de mercancías está siendo desbordada por conceptos mucho más complejos de interrelación económica. Lo que interesa hoy es la negociación sobre los factores de producción, el capital, el trabajo y la tecnología. La transnacionalización de la producción ha llevado a otorgar una mayor importancia a temas como la transferencia de tecnología, la eliminación de barreras a la inversión extranjera, la facilitación de la emigración calificada, la modernización del transporte y la comercialización de servicios relacionados con el comercio. El auge de una nueva forma de proteccionismo no arancelario a través de todo tipo de barreras como cuotas, consultas, trabas fitosanitarias, exigencias de calidad y restricciones aduaneras está demostrando la necesidad de encontrar nuevas formas de integración que superen los esquemas convencionales del intercambio comercial. España debe jugar el papel de punta de lanza de los intereses latinoamericanos en Europa equilibrando el área de influencia que a través de los países 
nórdicos, especialmente de Alemania, desempeñara Europa del Este. El desarrollo de formas conjuntas de producción y distribución en el espacio iberoamericano ayudará a la consolidación de un nuevo espacio económico benéfico para todos. La tarea se facilitará en la proporción y medida en que esté respaldada por tres instrumentos: una Cámara Empresarial, un sistema financiero regional y una red tecnológica.

\section{INICIATIVA PRIVADA, CAPITAL Y TECNOLOGIA}

El nuevo concepto de la integración supone la activa participación del sector privado en el desarrollo de las relaciones económicas. Esta idea se corresponde con la del mercado internacional de factores de producción. De lo que se trata entonces no es solamente de aumentar el intercambio comercial de bienes como de propiciar formas de articulación de intereses productivos entre los sectores privados de distintos países para ampliar sus espacios económicos de acción. Los empresarios privados son los nuevos protagonistas de la integración. Son ellos los que concretan, cristalizan y desarrollan los acuerdos marco a que llegan las agencias gubernamentales. La conformación de una red iberoamericana de empresarios tiene su justificación en estos argumentos, por supuesto, pero de manera considerable en la existencia ya evidente de una cultura empresarial iberoamericana, una tradición de relaciones de intercambio fortalecida por un lenguaje común y una misma idiosincracia de pensar y hacer negocios. Para Latinoamérica está mucho más cercana, en sus posibilidades de asimilación, la empresa española que la empresa europea industrializada. La pertenencia de España a la clase media europea facilita las posibilidades de conseguir acuerdos de integración al nivel microeconómico. Un instrumento idóneo para organizar esta relación, sería la constitución de una CAMARA IBEROAMERICANA reforzada por bancos de inversión, ruedas permanentes de negocios, bolsas de valores integradas, comités sectoriales de integración.

La inversión es el complemento necesario del esfuerzo de integración a nivel privado. El mercado de capitales latinoamericano se caracteriza por su debilidad y su contingencia; precisamente la crisis de la deuda se produjo por el excesivo endeudamiento económico frente a las casi nulas existencias de formas y recursos que autofinanciaran el desarrollo. El premio tributario al endeudamiento que consideraba los intereses como gastos frente al castigo fiscal de la capitalización, sumados a la escasa propensión al ahorro, contribuyeron a esta condición estructural de vulnerabilidad propia del mercado de capitales. Con la muy notable excepción del Banco Interamericano de Desarrollo, en la cual el peso condicionante de los Estados Unidos se ha hecho patente en los últimos años, no existen instrumentos financieros regionales sobre los cuales pudiera montarse una nueva estrategia de desarrollo para la región. Está la Corporación Andina de Fomento, el Banco Centroamericano, el Fondo del Río de la Plata, pero sus dimensiones no alcanzan la magnitud de los financiamientos requeridos ni están integrados entre sí. La decisión adoptada en principio por los Ministros de Economía de la Comunidad Económica Europea para el ingreso del Banco de Inversiones de Europa en Latinoamérica podría ser una excelente oportunidad para intentar, a través de un sistema de corresponsalías y con la participación de los intermediarios financieros regionales ya existentes, la adopción de un instrumento financiero en el área que apoye, efectivamente, los esfuerzos por la conformación de un tejido iberoamericano de intereses productivos y que financie los proyectos de modernización necesarios para la internacionalización de la economía en campos como el de infraestructura, comercialización, telecomunicaciones y tecnología.

\section{UN MERCADO COMUN DEL CONOCIMIENTO}

Está finalmente la necesidad de diseñar una RED TECNOLOGICA que permita la trasferencia de tecnología dentro del espacio iberoamericano. El conocimiento se ha convertido en el cuarto factor de la producción. Discusiones como las relacionadas con la propiedad intelectual, el pago de regalías, la apropiación de sistemas de software o la definición de la soberanía satelital tienen precisamente que ver con este aspecto. El Presidente del Uruguay con acierto visionario ha hablado de la necesidad de crear un mercado común del conocimiento. Un importante centro de investigaciones en los Estados Unidos trabajaba actualmente en el establecimiento de una red de supercomputadoras que entrelazaría a distintos centros universitarios en Latinoamérica con los ordenadores científicos de España. El proyecto, conocido ya como el "Proyecto Libertadores" permitiría una comunicación directa de las bases de datos científicos y tecnológicos para ser utilizados en función del progreso. El apoyo a un sistema de ciencia y tecnología que homologue las formas de producción, asimilación y difusión de tecnología en el área constituiría un invaluable aporte de la Cumbre a la configuración de una idea iberoamericana del desarrollo.

\section{LA LEGITIMIDAD}

Si la crisis latinoamericana de los años sesenta respondía a la búsqueda de la identidad, la crisis de la década que atravesamos se distingue por la búsqueda de la legitimidad. En la década de los ochenta se hicieron avances notables en el desarrollo de la democracia representativa pero muy pocos en la modernización del Estado, en la ampliación de las fronteras de la participación social, en la redistribución regional del poder nacional, en la tecnificación de la justicia y la maduración de los partidos políticos y organizaciones no gubernamentales. Como consecuencia de este vacío, los esfuerzos por mejorar las condiciones de distribución del ingreso fueron relativos. Mejoraron los índices sociales de alfabetismo, salubridad, escolaridad y vivienda pero creció el número de pobres absolutos en veintidós millones durante diez años y cayó el producto bruto por habitante. El desafío de la nueva idea latinoamericana es recuperar, a través de una acción decidida en el mejoramiento de las condiciones de vida de los latinoamericanos, la credibilidad 
perdída en las instituciones responsables del cambio. Asegurar por esta vía la supervivencia de una democracia amenazada hoy por múltiples enemigos externos en el continente. La tarea no es fácil. Porque no se trata simplemente de aumentar la inversión en escuelas o financiar más camas en los hospitales. De lo que se trata es de poner en marcha un nuevo esquema de cambio social apoyado en la participación comunitaria, la organización de los sectores informales frente a la consecución de sus necesidades, la asociación de las microempresas para consolidar sus posibilidades y oportunidades de progreso, en fin, de lo que se trata es de organizar la democracia para el cambio. En Colombia se han dado importantes pasos en la conformación de un nuevo sistema de desarrollo social a tráves del impulso de pequeños núcleos de familias, atendidos por madres con la asistencia de funcionarios del Estado; los núcleos comunitarios incorporan, bajo una misma óptica dinámica, distintos componentes de desarrollo educativo, atención al preescolar, salud preventiva y en algunos casos, un componente productivo de fami-empresa. Sobre esta cédula de cambio es posible construir todo un tejido de nuevas formulaciones sociales, menos burocráticas y más democráticas en su manejo. El impulso de una estrategia en esta dirección, definida en la Cumbre, favorecería de una manera notable el necesario proceso de legitimación social de la democracia que hoy enfrentan las naciones latinoamericanas.

Este ensayo debe terminar con una nota de optimismo sobre la próxima Cunbre Iberamericana. Para algunos, los quinientos años que acaban de transcurrir fueron años de tristezas y en el mejor de los casos, años de excesivas utopías irrealizables. Nada de malo hay en soñar cuando existe alguna posibilidad de convertir nuestros sueños en realidad. Esta posibilidad, la de convertir el sueño iberoamericano en realidad se nos presenta hoy como una realidad y un desafío. Como una oportunidad porque están dadas las condiciones para una productiva alianza entre la España europea y la América hemisférica. Como un desafío porque dependerá de la voluntad política de quienes, al sentarse en la Cumbre, tendrán en sus manos la posibilidad de decidir si en la próxima travesía de cinco siglos seguiremos juntos o separados. Mejor juntos, así lo manda la sangre. Y así lo dice la lengua que permite entendernos para comerciar y reflexionar, para pensar y crear. Para unirnos en fecundas diferencias.

\title{
RESUMEN
}

En este artículo, el autor señala las oportunidades que ofrece la celebración de la Cumbre Iberoamericana en la profundización y mejoramiento de la relación entre el hemisferio latinoamericano y España como parte de Europa. Con un tono optimista moderado, apunta los campos en los que esta relación puede ser más posible y más fructífera: el comercio, la cooperación empresarial, la tecnología y el conocimiento. El Plan Iberoamérica y el Foro Político son sólo el inicio de estas tendencias. Así mismo, se muestra confiado en que la Cumbre pueda apoyarse en una nueva idea latinoamericana que signifique un fortalecimiento de la democracia social.

\begin{abstract}
The author points out the opportunities that offer the Latin American Unit of Nations to be held at Madrid for Latin American Countries and Spain as part of Europe to deepen and improve their relations. With certain optimism it is shown the fields in with these relations can be possible and more fruitful: Trade, business cooperation, technology and knowledge. The Latin American Plan and the Political Forum are only the beginning of these tendencies. Likemore the author is hopeful that the Summit can be supported by a new Latin America idea wich means a strengthening of social democracy.
\end{abstract}

